\title{
HSV-1/HSV-2 Infection-Related Cancers in Bantu Populations Driving HIV-1 Prevalence in Africa: Tracking the Origin of AIDS at the Onset of the 20th Century
}

\author{
Jacqueline Le Goaster $^{a} \quad$ Patrice Bouree $^{a} \quad$ Franck N. El Sissy ${ }^{b}$ \\ Florence Phuong Buib Johanna Pokossy Epee ${ }^{b}$ Paul Rollin ${ }^{b}$ \\ Frédéric Tangy ${ }^{c}$ Anne-Lise Haenni ${ }^{d}$ \\ ${ }^{a}$ Department of Tropical Diseases, Hôpital Cochin C.H.U., University Paris V, Paris, France; \\ ${ }^{b}$ C.H.U., University Paris V, Paris, France; ${ }^{C}$ Viral Genomics and Vaccinations, CNRS, Pasteur \\ Institute, Paris, France; ${ }^{d}$ Jacques Monod Institute, CNRS, University of Paris VII, \\ Paris, France
}

\section{Keywords}

Sub-Saharan Africa - Bantu populations · Herpesviruses · HSV-1/HSV-2/HHV3 infections . HIV-1 prevention

\begin{abstract}
Introduction: At the onset of the 20th century, ancient clinical observations of cancer epidemics in Bantu populations of Sub-Saharan Africa were discovered. They were reported from 1914 to 1960, but remained unexplained. In 1983, in San Francisco, Calif., USA, cancer epidemics were related to infections by the human immunodeficiency virus type 1 (HIV-1) known as AIDS disease. Yet since 1996, it is known that HIV-1 strains are not the only ones involved. In Sub-Saharan Africa, recurrent orobuccal herpes simplex virus type 1 (HSV-1) and
\end{abstract}




\section{Case Reports in Oncology}

Case Rep Oncol 2016;9:815-825

DOI: $10.1159 / 00045093$

(C)

2016 The Author(s). Published by S. Karger AG, Basel www.karger.com/cro

Le Goaster et al.: HSV-1/HSV-2 Infection-Related Cancers in Bantu Populations Driving HIV-1 Prevalence in Africa: Tracking the Origin of AIDS at the Onset of the 20th Century

genital recurrent herpes simplex virus type 2 (HSV-2) appeared many times prior to infection by HIV-1. Case Reports: Data on these ancient medical observations regarding African cancer epidemics can today be referred to as the relationship between the unfortunate immune deficiency of herpes in Bantu populations and HIV-1 viral strains. For centuries, the Bantu populations dispersed in forests were living in close proximity to chimpanzees infected by simian immunodeficiency virus (SIV) and were exposed to SIV contamination which became HIV-1 in human beings. Presently, these unexplained Bantu cancer epidemics can be linked to the viral partnership of HSV-1/HSV-2 to HIV-1 strains. Conclusion: The key issue is now to prevent HSV-1/HSV-2 diseases related to HIV-1. An anti-herpes treatment administered early during childhood to Bantu populations will offer a mean of preventing herpes diseases related to HIV-1 infection and hence avoid cancer epidemics.

(C) 2016 The Author(s)

Published by S. Karger AG, Basel

\section{Introduction}

In the early 20th century, a large number of clinical observations of lymphomas and of Kaposi's sarcoma epidemics was reported in subtropical Africa. These publications were recently discovered in the library of the Saint-Louis Hospital in Paris, France. More than 400 publications precisely related to Kaposi's sarcomas were presented at a Symposium held in Kampala, Uganda, in 1961; they covered cases of cancer epidemics of the first half of the 20th century [1]. At that time, these cancer epidemics remained major unsolved enigmas.

In 1981, in San Francisco, Calif., USA, similarly to these earlier cancer epidemics, such epidemics were related to the discovery of HIV-1, genus Lentivirus, family Retroviridae, at the origin of AIDS disease. At about the same time, in 1996, these cancers, particularly Kaposi's sarcomas, were related to viruses of the Herpesviridae family [2, 3].

Then, at the end of the 90's, a link was reported between herpes simplex virus HSV$1 /$ HSV-2 and HIV-1 acquisition and transmission [4]. In 2007, the dialogue between HSV-2 and HIV-1 continued; genital herpesvirus diseases were shown to play an important role in driving HIV-1 prevalence in Africa [5, 6] and a relationship between recurrent herpesvirus diseases and HIV-1 was recognized. In 1981, the cancer epidemics observed in San Francisco could have had the same origin as those described at the onset of the 20th century in SubSaharan Africa where these cancer epidemics can now be related to both herpesviruses and to HIV-1.

In 2000, a phylogenetic tree of all members of the Herpesviridae family was published [7]. It provides a detailed view of the relationship existing between the herpesviruses of all mammalian organisms. The Herpesvirales constitute a large order of linear double-stranded (ds) DNA viruses that are natural hosts of all vertebrates and many other animals such as oysters.

At the fundamental level of virology, this tree reveals a close relationship between HSV1, HSV-2, and human herpesvirus 3 (varicella zoster virus or VZV or HHV-3) this last one infecting all human beings during childhood (fig. 1). This suggests a strong relationship between all members of Herpesviridae family, specifically between these last three herpesviruses, HSV-1/HSV-2/HHV3. Following this hypothesis, a first immune genetic anti-VZV defect could be at the origin of recurrent herpesvirus diseases such as oro-buccal and genital 


\section{Case Reports in Oncology}

herpesvirus diseases (HSV-1/HSV-2) as clinically observed, and that can be cured by antiherpes varicella therapy [8].

The herpes varicella disease (chickenpox or shingles) appears to be the partner of acquired immunological power of all human beings facing the numerous members of the Herpesviridae family.

At the origin of the recurrent HSV-1/HSV-2 herpesvirus diseases a preliminary anti-VZV or anti-HHV-3 virus immune defect could be observed at the serological level of herpes antibodies (Ab). This immunological herpes HSV1/HSV2 failure could be associated to other viruses of the Herpesviridae family defects preceding HIV-1 infections thus AIDS. These epidemics observed at the onset of the 20th century can now be related to a previous, primordial herpesvirus immune deficiency; such pathological associations of HSV-1/HSV-2 with HIV-1 strains appear to be at the origin of these ancient unsolved cancer epidemics $[7,9]$ (fig. 1).

\section{Sub-Saharan Cancer Epidemics}

Numerous members of the Herpesviridae family are pathogenic and related to diseases such as those produced by HHV-4/HHV-5/HHV-6/HHV-8. For instance, one should mention the potential role of the Epstein-Barr virus (EBV or HHV-4) on mononucleosis and on up to $40 \%$ of all Hodgkin's lymphomas [10]. HHV-5 is related to diseases of the cytomegalovirus, HHV-6 to Roseolovirus diseases, and Kaposi's sarcoma herpesvirus (KSHV or HHV-8) is related to Kaposi's sarcomas [5] (table 1).

At the same time at the end of the 20th century the suspected herpesviruses related to HIV-1 epidemics were demonstrated [4, 5]. Two herpesviruses, HHV-4 and HHV-8, were the biological cofactors of these cancers, related to HIV-1 strains.

Clinical lymphomas are often characterized by lymph nodes around the neck. The first lymphomas were described in 1872 by Hodgkin, but a specific type of lymphoma with a suspected herpes viral etiology, HHV-4, became equivalent to EBV, and was isolated by Burkitt in 1958 (table 1).

Congo appears as the epicenter of Kaposi's sarcomas and lymphoma epidemics among the Bantu tribes living in tropical African forests; outdoor workers have been the most frequently affected individuals [1] (table 2). Kaposi's sarcomas were histologically identified in 1914 in Bantus of Transvaal and Cameroon, with typical cases of Kaposi's sarcomas appearing as clinically unique at that time compared to the usual European or American Kaposi's sarcomas. In terms of contagion, incubation time, social class, low-age distribution and fatal evolution, African Kaposi's sarcomas were distinct from all European sarcomas although they already presented the same histology as European sarcomas. Kaposi's sarcomas appeared common among Black populations of Central Africa [9] (table 2) (fig. 2). However, they were unique in Europe and in the USA, and even though their Black populations originated from these African regions, they were free of such tumors. Indeed, the incidence of Kaposi's sarcomas related to the total number of malignancies appeared to be about 200 times more frequent in the Congo than in the city of Chicago, without any explanations at that time [10] (fig. 3). 


\section{Case Reports in Oncology}

As of the 1930's, many clinicians observed that Bantu outdoor workers were the selected targets of such cancer epidemics. An infectious viral origin had indeed been proposed as the cause of these cancer epidemics but it was impossible to prove it at that time. A resurgence of interest and investigation of Kaposi's sarcomas was stimulated by the high incidence of these cancers observed in South African histological samples analyzed in Johannesburg, South Africa.

The highest incidence of cancer epidemics is observed in the North Eastern region of the Congo basin, and in Uganda and Gabon. These countries are characterized by deep tropical rain forests providing perfect simian housing conditions and where the incidence of cancer epidemics in Bantu populations is high, accounting for $10 \%$ or more of all malignancies.

The infected Bantu hunters living in close proximity to noninfected Black and Indian populations have attracted special attention, tropical forests are sparsely populated thereby favoring co-sanguinity and their pathologies. At the onset of the 20th century, a large number of medical reports indicated that the frequency of Kaposi's sarcomas and lymphoma epidemics was decreasing in Savannah regions, and in sandier and drier regions. No forests, no chimpanzees, no hunters... Geographical conditions are thus necessary for chimpanzee housing and human-related infections [1] (fig. 1).

Specific environmental factors have played a key role in cancer epidemics in SubSaharan Africa [11]. These cancer diseases are most frequent in Transvaal and Natal, and frequent in Rhodesia (Zimbabwe) where the majority of the Bantu populations is composed of outdoor farmers living in forests; indeed, sanitary conditions were primitive, and barefootedness was the rule. The clinical features of Kaposi's sarcomas in Bantus were characterized by common sites of infection: feet, legs, and hands [12]. The thighs and forearms made up half the cases. This suggested an etiological role of chronic injury in Bantu hunters. No case was reported among booted Bantu clerks living in cities in South Africa [1].

The relative frequency of Kaposi's sarcomas between South African Whites and Bantus was also compared (table 2) (fig. 2). In the Belgian and Democratic Republic of Congo, out of a total of 2,623 cancers, there were 330 lymphomas (also known to be linked to HHV-4) and 242 Kaposi's sarcomas linked to HHV-8 [3] (fig. 3). In West Africa and in the Savannah and sandier regions such as Senegal and Ghana, out of a total of 1,884 cancers, there were 5 Kaposi's sarcomas and 229 lymphomas [13].

Immune genetic factors or infections may explain the distinction between Bantus living in forests and Bantus living in cities. The distribution of the disease appears geographical as well as genetic. It is now established that both factors interfere [1]. It should be noted that genetic studies present difficulties because of the loose family ties that exist among Bantus; indeed, a Bantu frequently takes on a new wife adopting her children. Thus, the proof of a genetically transmitted form of Kaposi's sarcomas is still missing [14].

For more than 3 centuries in Africa, migrant populations such as Whites and Indians have been relatively unaffected by Kaposi's sarcomas and lymphomas. 


\section{Case Reports in Oncology}

\section{Discussion}

The Relationship between Immune Genetic HSV-1/HSV-2 Herpes Defects and HIV-1 Strains Emerges as of the 2000's

It was established that Bantu hunters frequently exposed to the blood of chimpanzees can be infected by SIV. For centuries, primates are reservoirs for SIV, they carry SIV and thus can contaminate Bantu hunters and families. The question is: since when did SIV become HIV-1 in humans? When did AIDS as a zoonosis appear [15]?

Central Africa is the epicenter of SIV/HIV-1 [1] (fig. 1). HIV-1 exhibits the puzzling properties of inducing insidious diseases, persistence, latency, variation, recombination, and escape from immune pressure. HIV-1 infection appears to be a co-activator of microorganisms Pneumocystis jirovecii, Candida albicans, and of the Herpesviridae family, such as mainly lymphomas and Kaposi's sarcomas, as observed in the San Francisco cancer epidemics. 'Genital herpes has played a more important role than any other sexually transmitted infection in driving HIV-1 prevalence in Africa' [6].

At the end of the 20th century, transmission of pandemic HIV-1 contemporary to the sexually transmitted herpesvirus diseases HSV-1/HSV-2 leading to AIDS was established. These HIV-1 pandemic viruses have contaminated the African human populations living in tropical forests [12]. A genetically diverse set of SIVs is at the origin of human exposure to a plethora of other SIV-related viruses known to have infected African primates. They represent the natural reservoir of simian viruses: SIV represents an extremely large reservoir of lentiviruses with the potential of infecting other species, including humans.

Female chimpanzees breast-feed their babies for long periods, weaning occurring after 4 years $[16,17]$. If a female chimpanzee is infected by SIV during these 4 years of breastfeeding, the baby chimpanzee - as would a human baby - becomes contaminated and orphan animals are kept as pets in Bantu hunter families. In tropical Africa, human breastfeeding lasts 3-6 months with a maximum of 1-2 years; HIV-1 is transmitted by mothers in $4 \%$ of the cases at delivery, and in $40 \%$ of the cases during breast-feeding [16].

A long-standing virus-host relationship for over thousands of years has been suggested. As an example, the viruses hosted by four different African green monkey species have segregated into four distinct clusters during that time. The genetic divergence between these clusters could have occurred more recently emphasizing the zoonotic origins of these viruses in human beings. Similarities such as in viral genome sequences, phylogenetic relationships, prevalence in the natural host, geographic coincidence and routes of transmission indicate the axis of contamination between animals and humans. At least 18 distinct primate lentiviruses are known to infect African primates; in most cases natural lentiviral infections of primates are asymptomatic. Sooty mangabeys have been a source of food for human beings.

For more than a century, many distinct genetic mechanisms have been operating as responsible for the immune genetic power of all human beings to escape and survive attacks by the arrival of HIV-1 strains in Central Africa where chimpanzees constitute frequent opportunities for human beings to be in contact with infected animals [18]. In 2009, the situation was summarized as follows: '250 host-dependent factors were identified as playing a role in innate and adaptive immune HIV-1 response at the level of the mucosal barrier'; the 


\section{Case Reports in Oncology}

main objective was to shed light on the early pathogenic events that led to the HIV-1 pandemic $[19,20]$.

\section{Conclusions}

About 400 million years ago, viruses of the Herpesviridae family preceded the onset of the recent issue of HSV-1/HSV-2; the recent origin of HSV-1/HSV-2 is about 8 million years [7]. The genetic divergence between human primates and nonhuman primates has been set back 8 million to 5.5 million years. This is close to the period presented by paleoanthropologists as the time of the emergence of differentiation between primates and human species [16].

During childhood, the first herpesvirus VZV (HHV-3) participates in human evolution in terms of efficient acquired immune genetic HV3 Ab necessary throughout life for human species faced with members of the Herpesviridae family.

The Central African observations reported here highlight the important role played by the members of the Herpesviridae family at the beginning of the HIV-1 pandemic in tropical Africa and then disseminated worldwide. At the beginning of the 20th century, Bantu simian hunters could have presented an anti-VZV immunodeficiency and later they would have become victims of recurrent HSV-1/HSV-2 infections and then eligible for HIV-1 infections. Recurrent HSV-1/HSV-2 infections constitute biological co-factors in HIV-1 acquisition and transmission: they induce failure against other pathogenic herpesviruses such as HHV-4 and HHV-8 related to lymphomas and Kaposi's sarcoma involved in HIV-1 cancer epidemics. Enhancing HSV-1/HSV-2 immune defense could help to prevent recurrent herpes diseases able to push back HIV-1 diseases.

\section{Acknowledgments}

The authors thank Physiologie et Tumeur, an independent not-for-profit research Institution in Paris, France, for its support. They are also grateful to their colleagues and to Prof. Allan L. Goldstein, George Washington University, School of Medicine, Washington, D.C., USA, for their constant support.

\section{Statement of Ethics}

Since the manuscript concerned already published ancient data, there are no ethical conflicts to disclose.

\section{Disclosure Statement}

The authors declare no conflicts of interest. 


\section{References}

1 Oettle AG: Geographical and racial differences in the frequency of Kaposi's sarcoma as evidence of environmental or genetic causes; in Ackerman LV, Murray JF (eds): Symposium on Kaposi's Sarcoma. Basel, Karger, 1963, pp 17-50.

2 Russo JJ, Bohenzky RA, Chien MC, et al: Nucleotide sequence of the Kaposi's sarcoma-associated herpesvirus (HHV8). Proc Natl Acad Sci 1996;93:14862-14867.

3 Teo CG: Conceptual emergence of human a herpesvirus 8 (Kaposi's sarcoma-associated herpesvirus) as an oral herpes virus. Adv Dent Res 2006;19:85-90. Corey L, Wald A, Celum C, et al: The effects of Herpes simplex virus- 2 on HIV-1 acquisition and transmission: a review of two overlapping epidemics. J Acquir Immune Defic Syndr 2004;35:435-445. Corey L: Herpes simplex virus type 2 and HIV-1: the dialogue between the 2 organisms continues. J Infect Dis 2007; 195:1242-1244.

6 Abu-Raddad LJ, Magaret AS, Celum C, et al: Genital herpes has played a more important role than any other sexually transmitted infection in driving HIV prevalence in Africa. PloS One 2008;3:e2230.

7 McGeoch DJ, Dolan A, Ralph Adam A: Toward a comprehensive phylogeny for mammalian and avian herpesvirus. J Virol 2000;10401-10406. Le Goaster J, Gonzalo S, Bouree P, Tangy F, Haenni AL: Efficacy of the anti-VZV (anti-HSV3) vaccine in HSV1 and HSV2 recurrent herpes simplex disease: a prospective study. Open Access Journal of Clinical Trials 2012;4:51-58.

9 Hallenberger O: Multiple Angiosarkome der Haut bei einem Kamerunneger. Arch Schiffs Trop Hyg 1914;18:647-651.

10 Rothman S: Remarks on sex, age, and racial distribution of Kaposi's sarcoma and on possible pathogenetic factors; in Ackerman LV, Murray JF (eds): Symposium on Kaposi's Sarcoma. Basel, Karger, 1963, pp 13-16.

11 Wainwright J, Roach GG: Malignant neoplasic disease in Europeans, Africans and Indians in Natal. S Afr Cancer Bull 1957;1:162-170.

12 Clark MA: A report of fifty consecutives cases of malignant growths seen among the Wa-kikuyu. E Afr Med J 1948;25:123-125.

13 Smith EC, Elmes BG: Malignant disease in natives of Nigeria: an analysis of five hundred tumours. Ann Trop Med Parasit 1934;28:461-476. Gelfand M: Malignancy in the African. S Afr Med J 1949;23:1010-1016. Hahn B, Shaw GM, De Cock KM, Sharp PM: Aids as a zoonosis. Science 2000;287:607-617. Picq P: Les Origines de l'Homme. Paris, Tallandier, 2005, p 111.

17 Leakey R: The making of mankind. London, The Rainbird Publishing Group Ltd, ed 36 London, 1981, p 105.

18 Gao F, Bailes E, Robertson DL, et al: Origin of HIV-1 in the chimpanzee Pan troglodytes. Nature 1999;397:436-441.

19 Barré-Sinoussi F, Chermann JC, Rey F, et al: Isolation of a T-lymphotropic retrovirus from a patient at risk for acquired immune deficiency syndrome (AIDS). Science 1983;220:868-871.

20 Gallo R, Salahuddin SZ, Popovic M, et al: Frequent detection and isolation of cytopathic retroviruses (HTLV-III) from patients with AIDS and risk for AIDS. Science 1984;224:500-503.

-21 Findlay GM: Kaposi's multiple idiopathic hemorrhagic sarcoma. Trans Roy Soc Trop Med Hyg 1946;40:351-352.

22 Bah E, Parkin DM, Hall AJ, Jack AD, Whittle H: Cancer in the Gambia: 1988-97. Br J Cancer 2001;84:1207-1214. 


\section{Case Reports in Oncology}

Sites of medical centers of Kaposi's sarcomas and all cancers in Africans, both sexes, in tropical Africa. (1914-1960).

\section{B Sites of Bantu populations}

\section{Chimpanzee observatories}

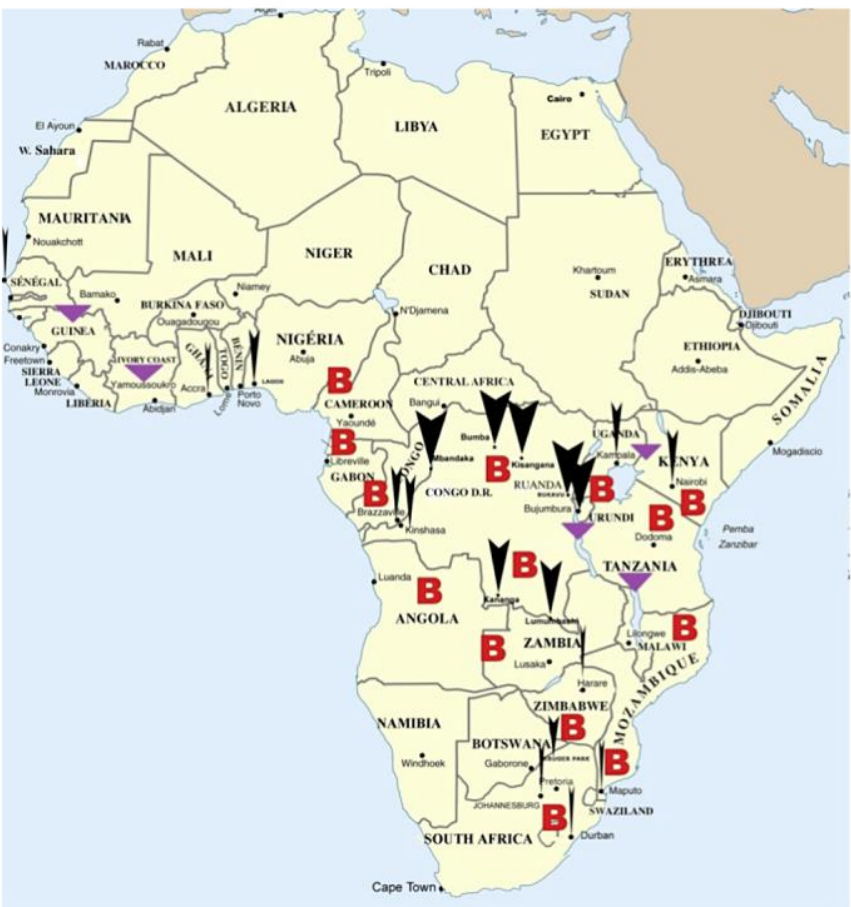

Fig. 1. Kaposi's sarcomas in tropical Africa. Correlation between Kaposi's sarcomas and Bantu ethnicities in Africa. Adapted from Oettle [1]. 


\section{Case Reports in Oncology}

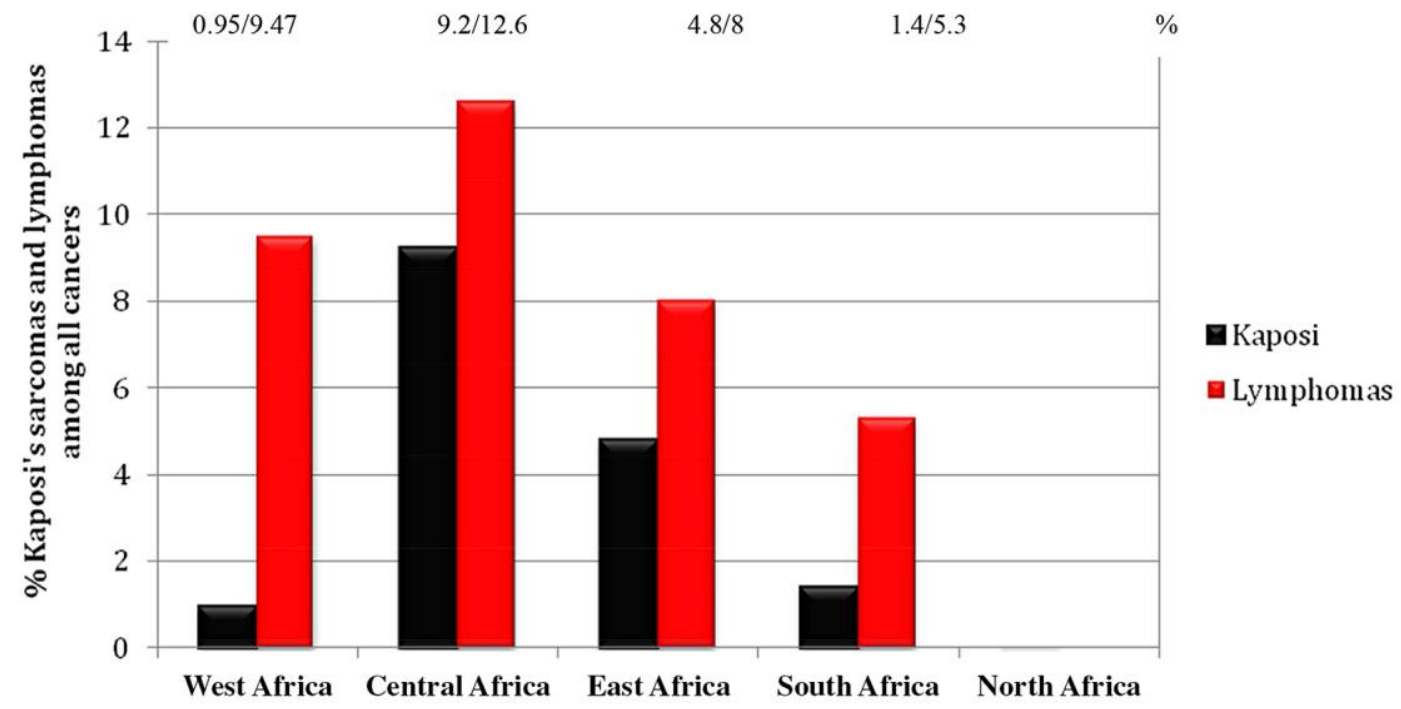

Fig. 2. Prevalence of Kaposi's sarcoma and lymphoma epidemics (1914-1960). Modified from Oettle [1]. Percentage of all cancers among Black African populations in both sexes, following the report by Findlay [21]. 


\section{Case Reports in Oncology}

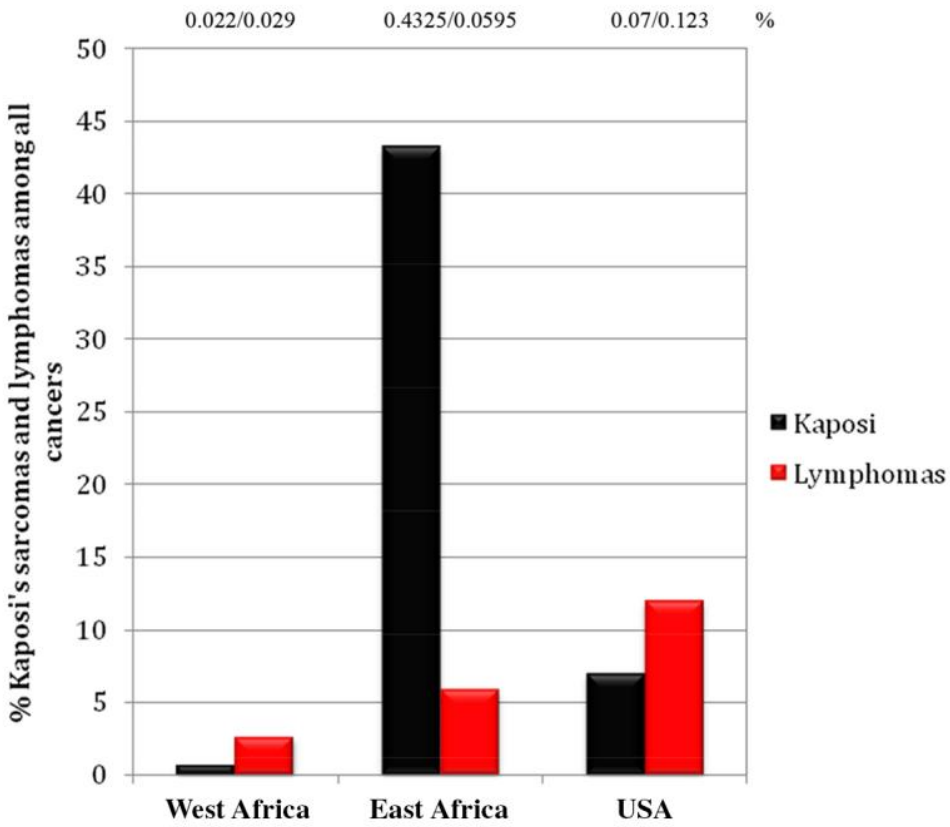

Fig. 3. Percentage of Kaposi's sarcoma and lymphoma epidemics among all cancers in males from 1988 to 1997 in Gambia, compared to the USA where at that time these cancers were related to AIDS diseases. Modified from Bah et al. [22].

Table 1. Summary of the known human pathogenic herpesviruses

HSV-1 Oro-buccal herpes

HSV-2 Genital herpes

VZV, Varicella zoster virus: HHV-3; the serodiagnostic level is the first step in establishing the basis

HHV-3 of the herpesvirus immunogenetic defense during childhood in all humans; during life, it can favor or not the immune ability when facing other pathogenic herpesviruses; the efficiency of the anti-HHV-3 vaccine against HSV-1/HSV-2 recurrences was observed [8]; does this immune genetic power also operate against the other herpesviruses?

HHV-4 Epstein-Barr virus: mononucleosis, Hodgkin lymphoma

HHV $-5 \quad$ Cytomegalovirus $=\mathrm{CMV}$, spontaneous abortion

HHV-6 Roseolovirus = Hashimoto thyroiditis, Pityriasis rosea and numerous other abnormalities

HHV-8 Kaposi's sarcoma 


\section{Case Reports in Oncology}

Table 2. Data on Kaposi's sarcomas presented at the Symposium held in Kampala, Uganda, 1961

\begin{tabular}{|c|c|c|c|c|}
\hline Region & Country (year) & $\begin{array}{l}\text { All cancers, } \\
\mathrm{n}\end{array}$ & $\begin{array}{l}\text { Kaposi's } \\
\text { sarcomas, } \\
\text { n }(\%)\end{array}$ & $\begin{array}{l}\text { Lymphomas, } \\
\text { n (\%) }\end{array}$ \\
\hline North Africa & Tunisia (1960) & 281 & $1(0.04)$ & $0(0.00)$ \\
\hline West Tropical Africa & $\begin{array}{l}\text { Senegal, Mali (1954) } \\
\text { Gold Coast, Ghana (1956) } \\
\text { Nigeria (1944) }\end{array}$ & 4,077 & $39(0.95)$ & $386(9.47)$ \\
\hline Central Tropical Africa & $\begin{array}{l}\text { Belgian Congo (1957) } \\
\text { Democratic Republic of Congo (1956) }\end{array}$ & 2,623 & $242(9.20)$ & $330(12.60)$ \\
\hline East Tropical Africa & $\begin{array}{l}\text { Tanzania (1960) } \\
\text { Uganda (1954) } \\
\text { Kenya (1948) } \\
\text { Mozambique (1957) } \\
\text { Zimbabwe (1949) }\end{array}$ & 3,006 & $145(4.80)$ & $242(8.00)$ \\
\hline South Africa & $\begin{array}{l}\text { Transvaal (1951) } \\
\text { Natal (1957) } \\
\text { Johannesburg residents (1953) } \\
\text { Johannesburg rural (1953) }\end{array}$ & 3,323 & $46(1.40)$ & $177(5.30)$ \\
\hline
\end{tabular}

Kaposi's sarcomas and lymphomas in Africa (1914-1960). Percentage of all cancers in histopathological series among Black populations in both sexes, following the report by Findlay [21]. 